\title{
Iodohexahydropyridoindolones. Formation and Reactivity
}

Rameshu Rallabandi, Somnath Jana and Jon D. Rainier*

Department of Chemistry

University of Utah

Salt Lake City UT, 84108

*corresponding author email: rainier@chem.utah.edu; phone 1-801-581-4954; fax 1-801581-8433

This manuscript is dedicated to the memory of Professor Harry H. Wasserman.

Abstract: Described herein is the generation and use of iodohexahydropyridoindolines and their free radical atom transfer reactions with aryl acetylenes to generate quaternary substituted pyridoindolones.

Key words: Indole, hexahydropyridoindolone, free radical reaction, atom transfer, natural products, kapakahine

In an effort to efficiently generate the hexahydropyrido-[2,3,b]-indolone ring system, we recently described the efficient synthesis of tetracyclic bromide $\mathbf{2}$ from a sequential Suzuki cross coupling and oxidative cyclization protocol. ${ }^{1,2}$ We envisioned that 2 would serve as a precursor to a wide range of potentially important small molecules having quaternary substitution through substitution of the bromide. ${ }^{3}$ However, and in contrast to the corresponding bromopyrroloindolines, ${ }^{4} 2$ has proven to be immune to reactions with nucleophiles.

Scheme 1. NBS Cyclization to Hexahydropyridoindolone 2<smiles>[R]N1C=C(c2ccccc2NC(F)(F)F)CCC1=O</smiles>

$\mathrm{R}=\mathrm{Bn}, \mathrm{Boc}$

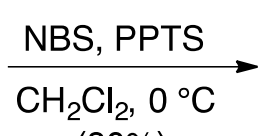

$(80 \%)$

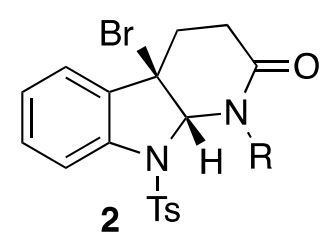

$\mathrm{R}=\mathrm{Bn}, \mathrm{Boc}$

Because of the difficulties alluded to above, we decided to explore an alternate approach to quaternary substituted pyridoindolones and decided to examine Baran's oxidative coupling technology using 1 . $^{5}$ While this methodology has been employed by the Baran group to build hetero-dimeric pyrroloindoline substrates and members of the kaphakahine family, to the best of our knowledge it has not been used to generate the corresponding hexahydropyridoindolones. With this in mind, we subjected $\mathbf{2}$ to iodoaniline and NIS and were pleased to generate hexahydropyridoindolone $\mathbf{5}$ in $90 \%$ yield. Because the corresponding unprotected iodopyrroloindolines had been reported to be unstable, ${ }^{6}$ it was interesting that the use of wet $\mathrm{CH}_{3} \mathrm{CN}$ in the reaction resulted in the formation of iodohexahydropyridoindolone $\mathbf{3}$ as the major product. ${ }^{7}$ Optimization of the conditions, namely excluding 4 from the reaction and carrying the reaction out in $\mathrm{CH}_{2} \mathrm{Cl}_{2}$ resulted in the isolation of $\mathbf{3}$ in $80 \%$ yield. 
Scheme 2. Oxidative Generation of Hexahydropyridoindolones
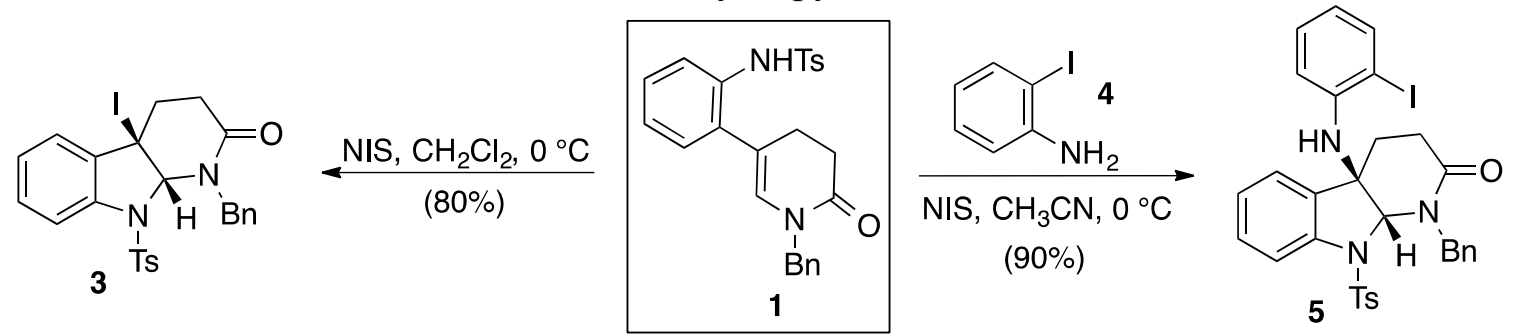

With a continued focus on quaternary substituted substrates, we became interested in the properties of iodide $\mathbf{3}$. In contrast to bromide $\mathbf{2}, \mathbf{3}$ served as a precursor to aniline and iodoaniline derivatives 5 (Table 1, entries 1-3). Surprisingly, even when care was taken to exclude $\mathrm{H}_{2} \mathrm{O}$, a significant by-product in these transformations was $3^{\circ}$ alcohol $\mathbf{6}$ (entry 3 ); it was the only product isolated when 3 was exposed to a mixture of $\mathrm{CH}_{3} \mathrm{CN}$ and $\mathrm{H}_{2} \mathrm{O}$ (entry 5). ${ }^{8}$ Because it would appear to be a likely olefin isomerization candidate, it was surprising to us that the elimination product 7 was stable (entry 3 ) and that it was the exclusive product when $\mathbf{3}$ was exposed to $3 \AA$ MS (entry 4). Pyridone 8 was generated as a by-product when 3 was exposed to iodoaniline (entry 1) or as the exclusive product when 3 was exposed to piperidine (entry 6).

Table 1. Iodohexahydropyridoindoline Reactions
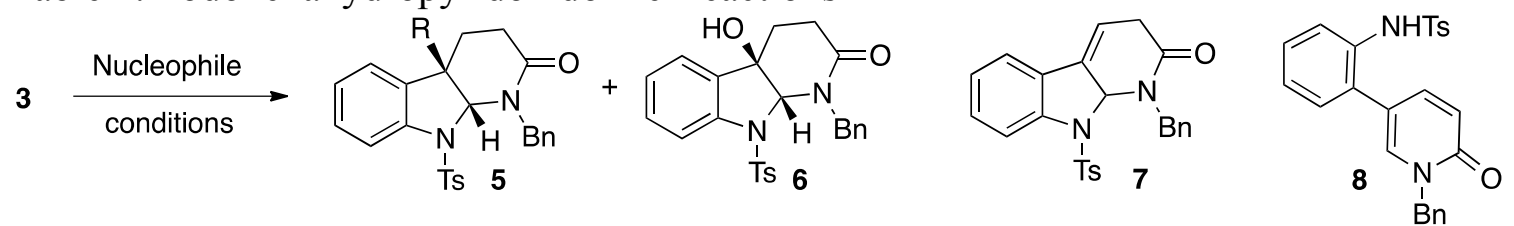

\begin{tabular}{|c|c|c|c|c|c|}
\hline ntry & Nucleophile & Conditions & $\mathrm{R}$ & $5: 6: 7: 8$ & Yield \\
\hline 1 & 2-iodoaniline & $\mathrm{CH}_{3} \mathrm{CN}$, & 2-iodoaniline & 3:3.3:0:1 & $75 \%$ \\
\hline 2 & 2-iodoaniline & $\mathrm{CH}_{2} \mathrm{Cl}_{2}$, reflux & 2-iodoaniline & 2.2:1:0:0 & $69 \%$ \\
\hline 3 & aniline & $3 \AA \AA \mathrm{MS}, \mathrm{CH}_{3} \mathrm{CN}, 40^{\circ} \mathrm{C}$ & aniline & 2.2:1:1.3:0 & $81 \%$ \\
\hline 4 & ---- & $3 \AA \AA \mathrm{MS}, \mathrm{CH}_{3} \mathrm{CN}, 40^{\circ} \mathrm{C}$ & --- & $0: 0: 1: 0$ & $79 \%$ \\
\hline 5 & $\mathrm{H}_{2} \mathrm{O}$ & $\mathrm{H}_{2} \mathrm{O}, \mathrm{CH}_{3} \mathrm{CN}(1: 1), 40^{\circ} \mathrm{C}$ & ---- & $0: 1: 0: 0$ & $80 \%$ \\
\hline 6 & piperidine & $3 \AA \AA \mathrm{MS}, \mathrm{CH}_{3} \mathrm{CN}, 40^{\circ} \mathrm{C}$ & piperidine & $0: 0: 0: 1$ & $81 \%$ \\
\hline 7 & ---- & $\mathrm{O}_{2}, \mathrm{BEt}_{3}, \mathrm{PhH}, 60^{\circ} \mathrm{C}$ & ---- & $0: 1: 0: 0$ & $72 \%$ \\
\hline
\end{tabular}

That $3^{\circ}$ alcohol 6 was formed even when water was excluded from the reaction implied that oxygen might be responsible for its formation. ${ }^{9,10}$ To explore this notion further we exposed 3 to oxygen in the presence of BEt 3 as a radical initiator. These conditions resulted in the generation of alcohol $\mathbf{6}$ in $72 \%$ yield even though normally employed reducing agents were absent from the reaction mixture (Table 1, entry 7). ${ }^{11}$

Cognizant of the free-radical chemistry of the corresponding bromopyrroloindolines and intrigued by the radical chemistry of $\mathbf{3},{ }^{12}$ we decided to determine whether halogensubstituted hexahydropyridoindolones were susceptible to free-radical induced $\mathrm{C}-\mathrm{C}$ and $\mathrm{C}-\mathrm{H}$ bond forming reactions. If these efforts were successful we felt that they would represent a rapid entry into quaternary substituted hexahydropyridoindolines. We initially examined the reaction of bromide $\mathbf{2}$ using allylstannane and were pleased to isolate 
quaternary substituted pyridoindoline $\mathbf{1 0}$ in $80 \%$ yield (Scheme 3 ). In a similar fashion, when 2 was exposed to $\mathrm{Bu}_{3} \mathrm{SnH}$ we isolated reduced pyridone 9 in $69 \%$ yield. While we have not examined all of the possibilities, the reaction of bromide 2 using free radical conditions appears to be limited to stannanes. Subjecting 2 to acrylate or activated alkynes and either $\mathrm{Bu}_{3} \mathrm{SnH}, \mathrm{AIBN}$ or atom transfer conditions using $\mathrm{BEt}_{3}$ as an initiator did not result in coupled products. ${ }^{13}$

Scheme 3. Free radical reduction and allyl addition using 2

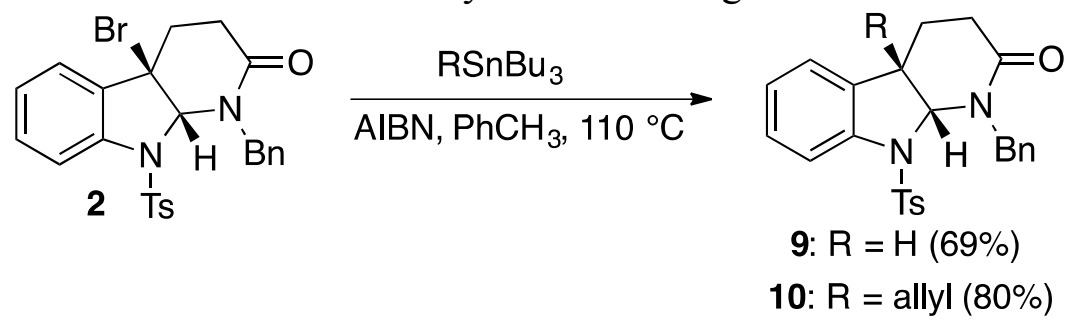

In contrast to $\mathbf{2}$, when $\mathbf{3}$ was exposed to atom transfer free radical conditions using phenyl acetylene and BEt 3 at $60{ }^{\circ} \mathrm{C}$ we isolated quaternary substituted hexahydropyridoindolone 12 in 67\% yield as a single stereoisomer (Table 2, entry 1). ${ }^{13,14}$ Interestingly and in spite of our attempts to exclude oxygen using freeze-pump-thaw techniques, we still isolated $\mathbf{6}$ as a by-product. We presume that this was due to the exothermic nature of the reaction of oxygen with the free radical from 3 and our inability to completely exclude $\mathrm{O}_{2}$ from the reaction mixture. ${ }^{15}$ By running the reaction at a higher substrate concentration $(0.2 \mathrm{mM})$ we completely avoided the generation of alcohol $\mathbf{6}$ but began to observe phenyl acetylene derived diene 13 (entry 2). Interestingly, when the reaction was carried out at $0.1 \mathrm{mM}$ vinyl iodide $\mathbf{1 2}$ was the only product isolated but its yield was still $70 \%$ (entry 3 ).

Table 2. Optimization of the Atom Transfer Reaction of $\mathbf{3}$ with Phenyl Acetylene

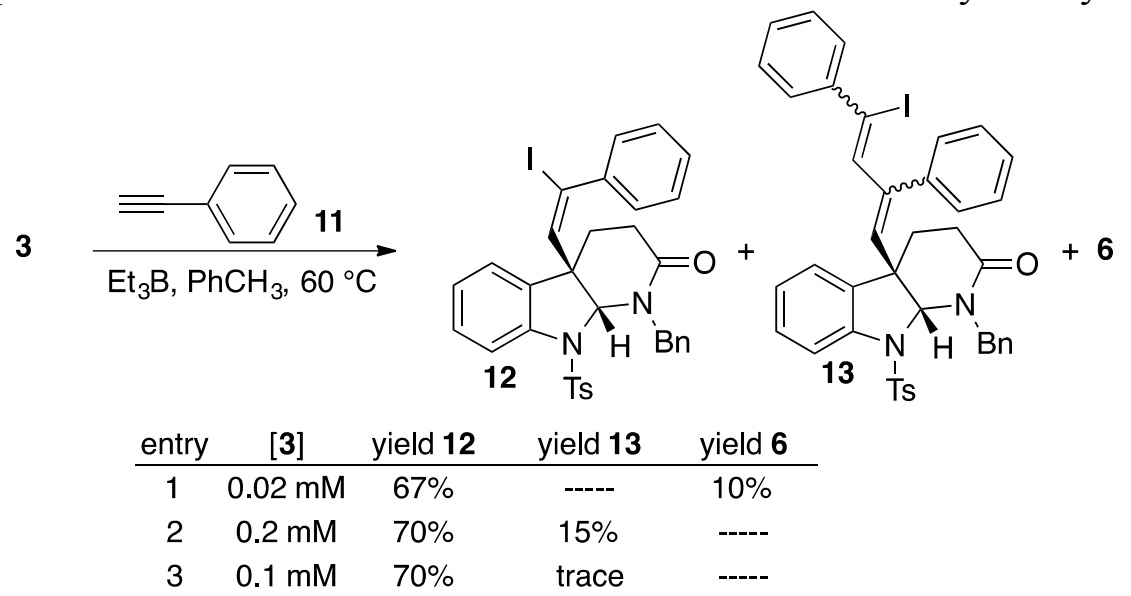

We explored the scope of the atom transfer reaction of $\mathbf{3}$ using the conditions that were optimized for phenyl acetylene by examining the effect of substitution at the paraposition of the aryl acetylene on the reaction. As illustrated in Table 3, the electronic environment about the acetylene did not significantly impact the yield for the reaction. Both electron rich and electron deficient aryl acetylenes underwent free radical coupling to give the corresponding quaternary substituted hexahydropyridoindolone in yields that ranged from $69 \%$ to $84 \%$.

Table 3. Scope of the Free-Radical Atom Transfer Reaction of $\mathbf{3}$ 


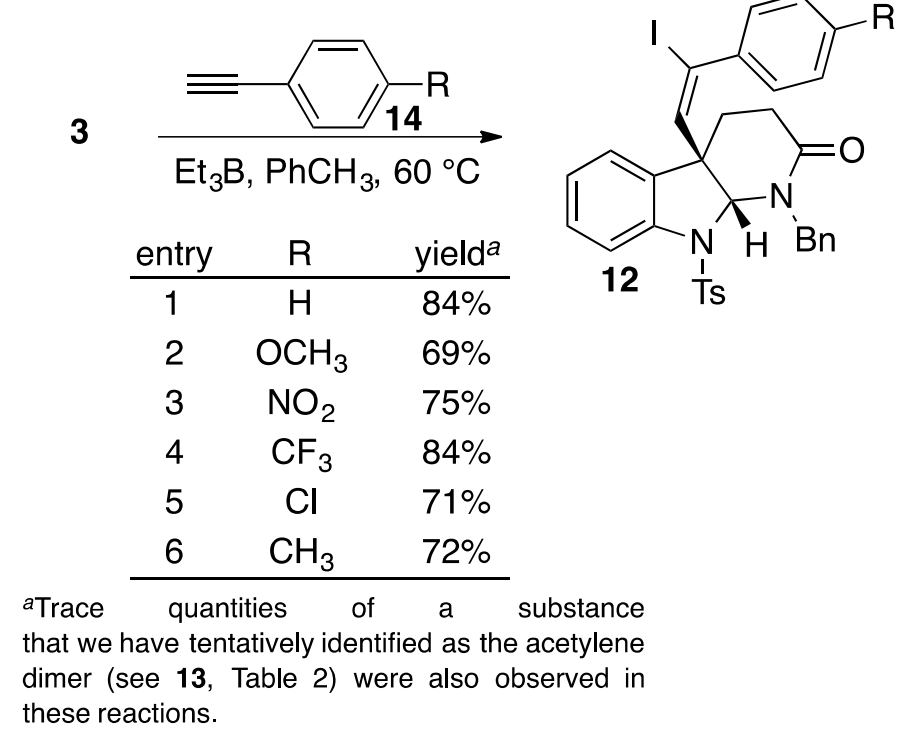

In conclusion, in this manuscript we have described the synthesis of iodohexahydropyridoindolone $\mathbf{3}$ and aniline substituted hexahydropyridoindolone $\mathbf{5}$ from dihydropyridone $\mathbf{1}$. We have also demonstrated that both bromo- and iodohexahydropyridoindolone successfully undergo free radical reactions to give quaternary substituted hexahydropyridoindolone substrates.

Acknowledgement The authors are grateful for the National Science Foundation (CHE 1012670) for support of this work. We would also like to thank Dr. Jim Muller (University of Utah) for mass spectrometry data and Dr. Peter Flynn (University of Utah) for assistance with NMR data. 


\section{Bibliography}

1. Jana, S.; Rainier, J.D. Org. Lett. 2013 15, 4426.

2. Natural products having this architecture include the kapakahines, see: Nakao, Y.; Yeung, B.K.S.; Yoshida, Y.W.; Scheurer, P.J. J. Am. Chem. Soc. 1995, 117, 8271. (b) Yeung, B.K.S.; Nakao, Y.; Kinnel, R.B.; Carney, J.R.; Yoshida, W.Y.; Scheuer, P.J.; Kelly-Borges, M. J. Org. Chem. 1996, 61, 7168. (c) Nakao, Y.; Kuo, J.; Yoshida, W.Y.; Kelly, M.; Scheuer, P.J. Org. Lett. 2003, 5, 1387.

3. For representative examples of synthetic efforts to the tetrahydropyridoindolone scaffold see: (a) Newhouse, T.; Lewis, C.A.; Baran, P.S. J. Am. Chem. Soc. 2009, 131, 6360.(b) Espejo, V.R.; Rainier, J.D. "Total Synthesis of Kapakahine E and F," Org. Lett. 2010, 12, 2154.

4. Espejo, V. R.; Rainier, J. D. J. Am. Chem. Soc. 2008, 130, 12894. (b) Espejo, V.R.; Li, X.-B.; Rainier, J.D. J. Am. Chem. Soc. 2010, 132, 8282.

5. Newhouse, T.; Baran, P.S. J. Am. Chem. Soc. 2008, 130, 10886.

6. Newhouse, T.; Lewis, C.A.; Eastman, K.J.; Baran, P.S. J. Am. Chem. Soc. 2010, 132,7119 .

7. It is likely that the presence of an electron-withdrawing group on the indoline $\mathrm{N}$ atom is important for the stability of $\mathbf{3}$. For representative examples of similarly substituted 3-bromo- and 3-chloropyrroloindolines that are stable see reference 12 and: (a) Taniguchi, M.; Gonsho, A.; Nakagawa, M.; Hino, T. Chem. Pharm. Bull. 1983, 31, 1856. (b) Yamada, F.; Fukui, Y.; Iwaki, T.; Ogasawara, S.; Okigawa, M.; Tanaka, S.; Somei, M. Heterocycles 2006, 67, 129. (c) Crich, D.; Banerjee, A. Acc. Chem. Res. 2007, 40, 151. (d) Movassaghi, M.; Schmidt, M.A.; Ashenhurst, J.A. Angew. Chem. Int. Ed. 2008, 47, 1485. (e) López, C.S.; Pérez-Balado, C.; Rodríguez-Graña, P.; de Lera, Á.R. Org. Lett. 2008, 10, 77. (f) Furst, L.; Narayanam, J.M.R.; Stephenson, C.R.J. Angew. Chem. Int. Ed. 2011, 50, 9655. (g) Ruiz-Sanchis, P.; Savina, S.A.; Acosta, G.A.; Albericio, F.; Álvarez, M. Eur. J. Org. Chem. 2012, 67. (h) Tu, D.; Ma, L.; Tong, X.; Deng, X.; Xia, C. Org. Lett. 2012, 14, 4830 .

8. Alcohol $\mathbf{6}$ is the core scaffold of the cytotoxic natural product chaetominine. See Jiao, R.H.; Xu, S.; Liu, J.Y., Ge, M.M.; Ding, H.; Xu, C.; Zhu, H.L.; Tan, R.X. Org. Lett. 2006, 8, 5709.

9. (a) Maillard, B.; Ingold, K.U.; Scaiano, J.C. J. Am. Chem. Soc. 1983, 105, 5095.

(b) Ohno, M.; Spande, T.F.; Witkop, B. J. Am. Chem. Soc. 1970, 92, 343.

10. Although mechanistically distinct from this work, Wasserman also described the use of oxygen to generate alcohols. See Wasserman, H.H.; Lipshutz, B.H. Tetrahedron Lett. 1975, 1731.

11. It is possible that the source of the hydrogen atom was BEt3. See Kihara, N.; Ollivier, C.; Renaud, P. Org. Lett. 1999, 1, 1419.

12. Bruncko, M.; Crich, D.; Samy, R. J. Org. Chem. 1994, 59, 5543.

13. Ichinose, Y.; Matsunaga, S.-i.; Fugami, K.; Oshima, K.; Utimoto, K. Tetrahedron Lett. 1989, 30, 3155-3158.

14. For a recent review describing free radical reactions of alkynes see Wille, $U$. Chem. Rev. 2013, 113, 813. 
15. Warning: A violent exotherm occurred when a dilute solution of BEt 3 was added dropwise to a solution of $3(20 \mathrm{mg})$ and toluene that had been saturated with oxygen. 